\title{
COMMITMENT SEBAGAI VARIABEL MEDIASI PENGARUH TRUST TERHADAP REPURCHASE INTENTION PADA RESTORAN WARALABA LOKAL
}

\author{
Sri Vandayuli Riorini \\ Fakultas Ekonomi, Universitas Trisakti, Jakarta \\ Email:rini_keloko@yahoo.co.id
}

\begin{abstract}
Franchising is a form of retail businesses, especially those of growing and promising restaurants. Competition is becoming more tightly multiplied by the entry of foreign franchisors. Customer loyalty is the key to win the competition. The purpose of this study is to analyze the trust, affective commitment, continuance commitment towards repurchase intention. Respondents as the sample of this study were 200 respondents who visited local franchise restaurants, chosen by using Purposive Sampling technique. Furthermore, the method of data analysis applies the Structural Equation Model techniques. The study finds that the entire hypothesis presented can be supported, where there are (1) a positive influence of trust towards affective commitment, (2) a positive influence of trust towards continuance commitment, (3) a positive affective trust towards repurchase intention, (4) a positive influence continuance commitment towards repurchase intention, and (5) a positive effect of trust towards repurchase intention. Furthermore, it is also found that (1) affective and continuance commitment is a mediator variable between the trust and repurchase intention, and (2) continuance commitment is a stronger factor in influencing the trust and repurchase intention than affective commitment. For further study, it is recommended that this research be applied to other types of local franchises, such as department stores, convenience stores, specialty stores, supermarkets and hypermarkets, as well as adding service quality and customer satisfaction as antecedents of trust and word-of-mouth as a consequence of the commitment.
\end{abstract}

Keywords : trust, affective commitment,continuance commitment, repurchase intention

Abstrak: Waralaba merupakan bentuk bisnis ritel khususnya restoran yang semakin berkembang dan menjanjikan. Persaingan menjadi semakin ketat ditambah masuknya franchisor asing. Loyalitas pelanggan merupakan kunci untuk memenangkan persaingan. Tujuan dari penelitian ini adalah untuk menganalisis Trust, Affective commitment, Continuance commitment terhadap Repurchase intention. Responden sebagai sampel dalam penelitian ini sebanyak 200 responden yang berkunjung ke restoran waralaba lokal, yang dipihih dengan menggunakan teknik Purposive sampling. Selanjutnya, metode analisis data menggunakan Teknik Structural Equation Model. Hasil penelitian menemukan bahwa seluruh Hipotesis yang dikemukakan dapat didukung, dimana (1) terdapat pengaruh positif Trust terhadap Affective commitment, (2) terdapat pengaruh positif Trust terhadap Continuance commitment, (3) terdapat pengaruh positif Affective trust terhadap Repurchase intention, (4) terdapat pengaruh positif Continuance commitment terhadap Repurchase intention, dan (5) terdapat pengaruh positif Trust terhadap Repurchase intention. Selanjutnya, ditemukan pula bahwa (1) Affective dan Continuance commitment merupakan variabel mediasi antara 
Trust dan Repurchase intention, dan (2) Continuance commitment merupakan faktor yang lebih kuat dalam mempengaruhi Trust, dan Repurchase intention dibandingkan Affective commitment. Untuk penelitian selanjutnya disarankan agar penelitian ini diterapkan pada jenis waralaba lokal lainnya, seperti department store, convenience store, specialty store, supermarket, dan hypermarket, serta menambahkan Service quality dan Customer satisfaction sebagai anteseden dari Trust dan Word-of-mouth sebagai konsekuensi dari Commitment.

Kata kunci: trust, affective commitment,continuance commitment, repurchase intention

\section{PENDAHULUAN}

Bisnis ritel di Indonesia merupakan bisnis yang semakin diminati pengusaha terutama di kota-kota besar. Pertumbuhan bisnis ritel di Indonesia setiap tahunnya antara 10\%-15\% (Aprindo / Asosiasi Perusahaan Ritel Indonesia), dengan penjualan mencapai Rp. 138 triliun pada tahun 2012 (Dunia Riset, 2013). Banyaknya usaha ritel disebabkan oleh perubahan pola konsumsi masyarakat serta tingkat pendapatan masyarakat yang terus meningkat (Fajri, 2012). Hal ini berdampak pada perubahan fungsi ritel yang bukan hanya sebagai tempat belanja tapi juga tempat bersosialisasi (Meryani, 2011).

Toko Waralaba (Franchise stores) merupakan tipe bisnis ritel berdasarkan ownership (kepemilikan bisnis) yang dibangun berdasarkan kontrak kerja waralaba (bagi hasil) antara investor perseorangan (independent bussines person / franchisee) dengan pewaralaba (franchisor). Bentuknya sangat beragam mulai dari bengkel, toko optikal, supermarket, dan restoran (Sujana, 2005).

Perkembangan waralaba di Indonesia, khususnya di bidang restoran sangat pesat. Menurut Sudarmiatin (2011), 40\% dari total omzet bisnis waralaba berasal dari penjualan di sektor restoran. Data Departemen Perindustrian dan Perdagangan Republik Indonesia, hingga tahun 2011 telah tedaftar sekitar 250 perusahaan penerima waralaba dimana 71 merupakan waralaba restoran terdaftar, dan 22 diantaranya waralaba restoran lokal. Pesatnya perkembangan waralaba restoran daerah perkotaan di Indonesia, karena didukung oleh jumlah populasi dan daya beli masyarakat yang tinggi, disamping pola makan masyarakat yang cenderung makan diluar rumah (Wardhana, 2012).

Semakin banyaknya jumlah waralaba restoran di Indonesia, ditambah masuknya pewaralaba asing / internasional (Tabel 1) dapat menimbulkan persaingan sesama waralaba restoran tersebut. Konsumen juga dapat dengan mudah berganti waralaba restoran yang dikunjungi, atau tetap loyal dengan satu waralaba restoran.

Untuk memenangkan persaingan, setiap perusahaan harus dapat menciptakan loyalitas pelanggan (Kotler \& Keller, 2011). Loyalitas pelanggan merupakan kunci keunggulan bersaing (Bharadwaj et al., 1993), serta menjaga kesinambungan perusahaan/ kemampu-labaannya terus menerus (Morgan \& Hunt, 1994; Reichheld, 1996). Loyalitas penting karena dapat memberikan suatu outcome, yaitu: Repurchase intention (Liang \& Wang, 2005). Loyalitas mempunyai hubungan positif dengan profitabilitas (Rowley \& Dawes, 1999; Terril et al., 2000). Reichheld \& Sasser (1990) menemukan bahwa “...when a company retains just 5 percent more of its customers, profits increase by 25 percent to 125 percent." Peningkatan profit tersebut berasal dari penurunan biaya pemasaran dan operasional, serta peningkatan penjualan. 
Tabel 1. Waralaba Restoran Terdaftar di Indonesia Berdasarkan Asal Negara dan Nama sampai dengan Tahun 2011

\begin{tabular}{|c|c|c|c|}
\hline No. & Negara Asal & Nama Restoran Waralaba & \\
\hline \multirow[t]{12}{*}{1.} & Indonesia & 1. Adem Ayem & 12. Gado-Gado Boplo \\
\hline & & 2. Ayam Bakar Wong Solo & 13. Hoka Hoka Bento \\
\hline & & 3. Ayam Goreng Fatmawati & 14. J.CO Donuts \\
\hline & & 4. Ayam Goreng Mbok Berek & 15. Papa Ron's Pizza \\
\hline & & 5. Ayam Goreng Suharti & 16. Roti Boy \\
\hline & & 6. Bakso Lapangan Tembak & 17. Roti bakar SAM \\
\hline & & Senayan & 18. Sate Khas Senayan \\
\hline & & 7. Bakmi GM & 19. Sederhana Restoran \\
\hline & & 8. Bebek Goreng Abah Ndut & Masakan Padang \\
\hline & & 9. Bu Tjitro & 20. Solaria \\
\hline & & 10. California Fried Chicken & 21. Sour Sally \\
\hline & & & 22. Wong Solo \\
\hline \multirow[t]{13}{*}{2.} & Amerika & 1. $\mathrm{A} \& \mathrm{~W}$ & 14. McDonald's \\
\hline & Serikat & 2. Arby's & 14. Restoran Pizza \\
\hline & & 3. Burger King & 15. Popeyes \\
\hline & & 4. Baskin Robbins & 16. Porn Burger \\
\hline & & 5. Dairy Queen & 17. Quickly \\
\hline & & 6. Domino's Pizza & 18. Starbucks \\
\hline & & 7. Dunkin' Donuts & 19. Subway \\
\hline & & 8. Gloria Jean's Coffees & 20. Taco Bell \\
\hline & & 9. Hartz Chicken Buffet & 21. Taco Time \\
\hline & & 10. Jack in the Box & 22. The Coffee \\
\hline & & 11. Kentucky Fried Chicken & Tea Leaf \\
\hline & & 12. Krispy Kreme & 23. Wendy's \\
\hline & & 13. Manchu Wok & 24. Yogen Früz \\
\hline \multirow[t]{3}{*}{3.} & Jepang & 1. Ajisen Ramen & 4. Yoshinoya \\
\hline & & 2. Hanamasa & \\
\hline & & 3. MOS Burger & 5. Beef Bowl \\
\hline \multirow[t]{5}{*}{4.} & Kanada & 1. A\&W Kanada & 6. Swiss Chalet \\
\hline & & 2. Arby's & 7. Tim Hortons \\
\hline & & 3. Country Style & 8. White Spot \\
\hline & & 4. Dixie Lee Fried Chicken & 9. Yogen Früz \\
\hline & & 5. New York Fries & \\
\hline \multirow[t]{2}{*}{5.} & Malaysia & 1. Bread Story & \\
\hline & & 2. Secret Recipe & \\
\hline \multirow[t]{3}{*}{6.} & Singapura & 1. BreadTalk & 4. Old Chang Kee \\
\hline & & 2. Bengawan Solo (perusahaan) & 5. Ya Kun Kaya Toast \\
\hline & & 3. Kopi Tiam & \\
\hline 7. & Mexico & 1. El Pollo Loco & \\
\hline 8. & Australia & 1. La Porchetta & \\
\hline 9. & Afrika Selatan & 1. Nando's & \\
\hline 10. & Guatemala & 1. Pollo Campero & \\
\hline
\end{tabular}

Sumber: http://Daftar_waralaba_rumah_makan.org

Menurut Lacey \& Morgan (2009), Repurchase intention / niat untuk membeli kembali merupakan hasil dari perilaku pelanggan yang berkomitmen. Pelanggan yang 
berkomitmen tidak hanya diharapkan untuk mempertahankan hubungan bisnis, tetapi untuk meningkatkan aktivitas pembelian dari waktu ke waktu (Gronroos, 2004). Jika perusahaan membentuk hubungan yang baik, kedua belah pihak pasti akan setuju untuk melanjutkan komitmen. Sebaliknya, jika hubungan ini tidak dipertahankan dengan upaya terbaik dari perusahaan, maka akan berdampak pada tingginya niat pelanggan untuk pindah ke perusahaan lain (Wang, 2009).

Commitment dibentuk karena adanya kepercayaan konsumen. Pengalaman positif setelah konsumen mengkonsumsi suatu merek atau produk akan memperkuat persepsi dan kepercayaan konsumen tentang kualitas produk yang ditawarkan perusahaan (Albari, 2012). Garbarino \& Johnson (1999) berpendapat ketika konsumen mempercayai perusahaan, konsumen akan meyakini kualitas dan kehandalan dari produk atau jasa yang ditawarkan. Trust merupakan faktor yang memungkinkan timbulnya kesetiaan konsumen yang didasari oleh pengalaman konsumen berbelanja dalam bentuk keinginan untuk mengunjungi perusahaan dan membeli kembali (Singh, 1991). Jika satu pihak percaya pada pihak lain, maka pihak yang percaya akan membangun suatu bentuk perilaku positif terhadap pihak yang dipercayai. Hal ini berarti, bila pelanggan mempercayai suatu merek, maka akan membentuk minat membeli kembali yang positif terhadap merek yang dipercayai (Lau \& Lee, 1999).

Berdasarkan uraian diatas maka masalah dapat dirumuskan sebagai berikut: (1) Apakah terdapat pengaruh Trust terhadap Commitment, Repurchase intention, dan (2) Apakah terdapat pengaruh Commitment terhadap Repurchase intention.

\section{KAJIAN TEORI}

Trust merupakan faktor penting untuk menjaga hubungan yang baik antara penjual dengan pembeli (Gundlach et al., 1995), dan mendorong hubungan jangka panjang dengan dan antara mitra bisnis (Zur et al., 2012). Kesediaan untuk mengandalkan kemampuan, integritas dan motivasi pihak lain untuk bertindak dalam rangka memuaskan kebutuhan dan kepentingan seseorang menggambarkan bahwa orang tersebut memiliki kepercayaan / Trust (Sheth \& Mittal, 2004). Menurut Callaghan et al., (1995), Trust dalam pemasaran ritel lebih menekankan pada sikap individu yang mengacu pada keyakinan konsumen atas kualitas dan kehandalan layanan pe-ritel yang diterimanya. Garbarino \& Johnson (1999) berpendapat ketika konsumen mempercayai perusahaan, konsumen akan meyakini kualitas dan kehandalan dari jasa yang ditawarkan tersebut. Chow \& Holden (1997) mengatakan semakin terpercaya suatu hubungan, semakin tinggi nilai yang diberikan konsumen dalam suatu hubungan, akibatnya konsumen memiliki perilaku yang lebih positif / komit terhadap perusahaan. Trust terhadap retailer didasarkan pada informasi apa yang didapatkan oleh konsumen mengenai retailer (Bloemer \& de Ruyter, 1998). Kepercayaan dengan retailer akan memiliki dampak positif bagi perilaku konsumen melalui pembelian terhadap produk-produk yang ditawarkan, bahkan konsumen akan membeli lebih banyak (Morgan \& Hunt, 1994).

Menurut McAllister (1995), Trust dapat dikategorikan pada dua dimensi yaitu Cognitive trust dan Affective trust. Affective trust merupakan tingkat kepercayaan dari satu individu atas dasar perasaan atau faktor emosional dan perhatian yang ditunjukkan serta merupakan kepercayaan jangka panjang antara dua pihak (McAllister, 1995). Sedangkan Cognitive Trust merupakan keyakinan atau kesediaan pelanggan mengandalkan kompetensi dan kehandalan penyedia layanan (Moorman et al., 1992). Dalam perusahaan 
ritel, Cognitive trust muncul dari pengetahuan, pengamatan, reputasi dan bahkan pengalaman pribadi dengan pengecer (Eastlick \& Lotz, 2011). Jika pelanggan percaya bahwa pengecer handal dan memiliki pengetahuan, keterampilan, serta keahlian untuk memenuhi janjinya, maka pelanggan akan merasakan Cognitive trust tersebut (Kenning, 2008). Twing-Kwong et al., (2013) mengatakan bahwa Cognitive trust dan Affective trust berpengaruh positif dengan komitmen pelanggan di masa depan.

Commitment menjadi sebuah faktor penting dan menjadi bagian integral dalam kelangsungan bisnis jangka panjang maupun kesuksesan perusahaan untuk menjalankan berbagai strategi bisnis dengan baik (Day, 2000; Gundlach et al., 1995; Morgan \& Hunt, 1994). Konsumen yang mempunyai niat yang terus menerus membangun dan mempertahankan hubungan jangka panjang dikatakan memiliki komitmen (Moorman et al., 1992). Komitmen bukan hanya sebuah karakter penting untuk menjaga hubungan yang baik dan berjangka panjang, tetapi juga sebuah ekspresi dari kerelaan konsumen untuk tetap bertahan (loyalty) dengan penjual tersebut (Hennig-Thurau et al., 1997). Kepercayaan merupakan konsep utama dari hubungan pertukaran karena suatu hubungan yang didasari dengan kepercayaan diyakini akan membuat pihak-pihak tersebut komit dalam hubungan. Kepercayaan-komitmen, merupakan dua faktor yang tidak dapat dipisahkan. Kepercayaan merupakan penentu utama dari komitmen hubungan. Kepercayaan dapat menuntun kepada komitmen, karena kepercayaan menciptakan hubungan pertukaran yang bernilai tinggi yang dapat mengarahkan kepada efisiensi, produktivitas dan efektifitas dalam suatu hubungan (Morgan \& Hunt, 1994).

Dalam konteks hubungan pemasaran, Commitment sebaiknya dilihat sebagai multiple components (Gundlach et al., 1995). Meyer \& Allen (1997), mengemukakan tiga dimensi dari komitmen, yaitu: (1) Affective Commitment - merupakan dorongan yang didasarkan pada hasrat/keinginan (desire-based) untuk tetap berada dalam organisasi. Menurut Meyer \& Smith (2000) Affective commitment merefleksikan dorongan emosional, mengenal dan ikut serta dalam organisasi. (2) Continuance commitment - merupakan dorongan yang didasarkan atas kebutuhan yang mengikat seseorang dengan perusahaan. Continuance commitment dapat berkembang karena adanya berbagai tindakan atau kejadian yang dapat meningkatkan kerugian jika meninggalkan suatu merek. Beberapa tindakan atau kejadian ini dapat berupa investasi (sesuatu yang berharga, termasuk waktu, usaha ataupun uang), alternatif kemungkinan untuk membeli merek lain, dan proses pertimbangan dimana konsumen telah mencapai kesadaran bagaimana dampaknya bagi mereka sendiri jika meninggalkan merek tersebut (Meyer \& Allen, 1997). (3) Normative commitment - menjelaskan tentang kekuatan yang mengikat seseorang dengan perusahaan karena kewajiban yang dirasakan. Dikaitkan dengan merek, maka Normative commitment - menjelaskan tentang kekuatan yang mengikat konsumen dengan merek karena kewajiban yang dirasakan. Dalam konteks konsumen, Normative commitment mengakibatkan konsumen tetap bertahan dengan penyedia jasa karena mereka merasa "wajib / seharusnya". Hal ini muncul karena konsumen percaya bahwa merek akan memberikan sesuatu yang sangat berharga bagi dirinya yang tidak dapat dibalas kembali, sehingga konsumen merasakan kewajiban untuk terikat dengan merek (Meyer \& Allen, 1997). Dalam penelitian ini, digunakan 2 dimensi commitment konsumen restoran, yaitu: Affective commitment dan Continuance commitment. Normative tidak bisa diterapkan pada hubungan antara konsumen dengan merek karena kewajiban, sifatnya "memaksa", sedangkan tidak ada satupun, bahkan merek sekalipun yang dapat memaksa konsumen berkewajiban untuk merasa terikat/komit walaupun merek tersebut telah memberikan 
sesuatu yang sangat berharga bagi dirinya. Jadi, konsumen merasa terikat/komit terhadap merek timbul karena dorongan yang "diciptakan", yaitu dorongan emosional maupun dorongan atas dasar kebutuhan dimana konsumen percaya bahwa mereka tidak dapat mengakhiri hubungan tersebut karena biaya-biaya ekonomis (switching cost), sosial dan psikologis. Pelanggan yang berkomitmen tidak hanya diharapkan untuk mempertahankan hubungan bisnis, tetapi untuk meningkatkan aktivitas pembelian dari waktu ke waktu (Gronroos, 2004). Jika perusahaan membentuk hubungan yang baik, kedua pihak pasti akan setuju untuk melanjutkan komitmen. Sebaliknya, jika hubungan ini tidak dipertahankan dengan upaya terbaik dari perusahaan, maka akan berdampak pada tingginya niat pelanggan untuk pindah ke perusahaan lain (Wang, 2009).

Repurchase intention merupakan perilaku yang muncul sebagai respon terhadap suatu objek. Niat (intention) merupakan hasil perilaku seseorang sebelum melakukan suatu tindakan (overt action), yang dapat dijadikan dasar untuk meprediksi perilaku tindakan tersebut (Ardhanari, 2008). Niat pembelian kembali mengacu pada kesediaan konsumen untuk membeli lebih banyak dari sebuah perusahaan (Gounaris et al., 2010) dan penilaian individu tentang membeli lagi layanan dari perusahaan yang sama, dengan mempertimbangkan situasi dan keadaan saat ini (Lacey \& Morgan, 2009).

Penelitian sebelumnya menjelaskan peran penting Repurchase intention sebagai kunci dari hasil perilaku konsumen untuk hubungan pemasaran yang sukses (Reichheld, 1996). Hal ini dikarenakan, Repurchase intention merupakan kecenderungan untuk menggunakan kembali layanan dari perusahaan di masa yang akan datang (Jones et al., 2003), perilaku yang menunjukkan keinginan untuk membeli kembali suatu produk atau jasa (Mittal \& Lassar 1998), keputusan pelanggan untuk terus menggunakan penyedia jasa yang sama (Zeithaml \& Bitner, 1996), penilaian individu untuk membeli kembali suatu bentuk jasa dari perusahaan yang sama, yang dapat diandalkan pada situasi atau keadaan tertentu (Hellier et al., 2003), dan suatu bentuk penilaian terhadap kepuasan aktual dari konsumen yang setia (Koufaris, 2002).

Griffin (1995) menjelaskan siklus pembelian (Purchase Cycle) yang dilalui oleh konsumen hingga sampai ke tahap repurchase. Tahapan-tahapan tersebut adalah: (1) Awareness (kesadaran), dalam tahap ini perusahaan memulai dengan membagi pengetahuan yang dibutuhkan untuk menggerakkan produk dan jasa perusahaan selangkah lebih ke depan di dalam pikiran prospektif konsumen. Kesadaran dapat terjadi melalui berbagai macam cara, seperti melalui iklan (advertising), surat kabar (newspaper), Katalog (catalog), informasi dari orang lain (word-of-mouth), dan kegiatan pemasaran. (2) Initial Purchase (pembelian pertama), merupakan langkah yang sangat krusial dalam kemampuan perusahaan untuk menumbuhkan loyalitas, pembelian pertama adalah percobaan dan perusahaan dapat memberikan kesan produk yang positive atau negative terhadap konsumennya. Ketika pembelian pertama sudah dilakukan, maka perusahaan memiliki kesempatan dengan sungguh-sungguh mulai menumbuhkan konsumen yang loyal. (3) Post Purchase Evaluation (evaluasi setelah pembelian), setelah pembelian dilakukan oleh konsumen, secara sadar atau tidak sadar mereka mengevaluasi transaksi tersebut. Jika konsumen merasa puas atau tidak puas untuk mempertimbangkan perpindahan kepada pesaing, dalam tahap ini keputusan untuk membeli kembali mungkin terjadi. (4) Decision to Repurchase (keputusan untuk membeli kembali), komitmen untuk membeli lagi merupakan sikap yang sangat krusial terhadap loyalitas bahkan lebih penting dari kepuasan. Motivasi untuk melakukan pembelian kembali datang dari sikap menyukai produk atau jasa yang lebih baik, secara potensial keputusan untuk melakukan pembelian 
kembali sering terjadi pada saat pertama ketika konsumen merasa memiliki ikatan emosional dengan produk tersebut. (5) Repurchase (pembelian kembali), tahap akhir dalam proses ini adalah pembelian kembali yang sesungguhnya merupakan syarat untuk dipertimbangkan menjadi pelanggan loyal, pelanggan yang membeli lagi produk yang sama, mengulangi tahap tiga sampai lima berulang kali.

Kerangka Konseptual. Berdasarkan uraian diatas maka untuk mempermudah pemahaman pada penelitian yang dilakukan, berikut Rerangka Konseptual digambarkan secara skematis di bawah ini:

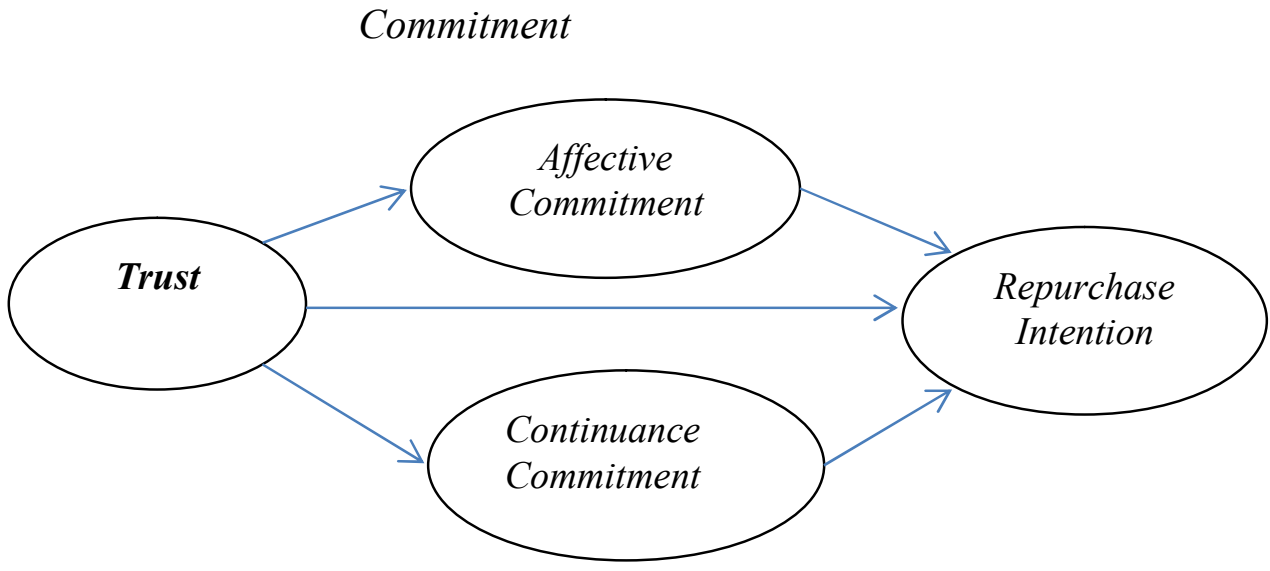

Gambar 1. Skema Kerangka Konseptual

Perumusan Hipotesis. Berdasarkan teori-teori yang telah dikemukakan diatas, maka Hipotesis yang akan diuji dapat dikemukakan sebagai berikut:

$\mathrm{H}_{1}$ : Terdapat pengaruh positif Trust terhadap Affective commitment.

$\mathrm{H}_{2}$ : Terdapat pengaruh positif Trust terhadap Continuance commitment.

$\mathrm{H}_{3}$ : Terdapat pengaruh positif Affective commitment terhadap Repurchase intention.

$\mathrm{H}_{4}$ : Terdapat pengaruh positif Continuance commitment terhadap Repurchase intention.

$\mathrm{H}_{5}$ : Terdapat pengaruh positif Trust terhadap Repurchase intention.

\section{METODE}

Penelitian yang dibuat mengacu pada penelitian sebelumnya yang dilakukan oleh Twing-Kwong et al., (2013) dan Mosavi \& Ghaedi (2012). Rancangan penelitian yang digunakan adalah Hypothesis Testing. Data dikumpulkan pada bulan Oktober 2015.

Terdapat 3 variabel yang digunakan dalam penelitian, yaitu, (1) Trust, (2) Commitment, dan (3) Repurchase intention. Seluruh variabel diukur dengan menggunakan alat ukur dari sumber yang jelas berdasarkan teori, dimana: (1) Trust diukur dengan menggunakan 2 (dua) dimensi yang diadaptasi dari Twing-Kwong et al., (2013) yaitu: (a) Cognitive trust dan (b) Affective trust, dimana masing-masing dimensi diukur dengan menggunakan sejumlah item pernyataan. (2) Commitment, juga diukur dengan 2 dimensi yang diadaptasi dari Louis \& Lombart (2010), yaitu : (a) Affective commitment dan (b) Continuance commitment. Selanjutnya masing-masing item pernyataan digunakan untuk mengukur masing-masing dimensi (3) Repurchase intention diukur dengan menggunakan tiga item pernyataan yang diadaptasi dari Mosavi \& Ghaedi (2012). Selanjutnya, 
selanjutnya, responden dalam menjawab seluruh item pernyataan dengan alternatif jawaban yang dipilih menggunakan Skala Likert 5 point, yaitu dari 1 sampai dengan 5, dimana 1 menyatakan Sangat Tidak Setuju, sampai dengan 5 bila menjawab sangat setuju. Semakin tinggi penilaian responden semakin tinggi persepsi terhadap variabel penelitian.

Kuesioner yang merupakan instrumen penelitian yang digunakan dalam penelitian diujikan terlebih dahulu untuk mendapatkan data yang baik dengan melakukan Uji Validitas dan Uji Reliabilitas. Uji Validitas menggunakan construct validity, yang menjelaskan pemahaman argumentasi teoritik yang melandasi pengukuran yang diperoleh. Pengujian Construct validity dilakukan dengan menggunakan Pearson product moment, yaitu pengukuran yang berkaitan dengan sejauh mana suatu skala pengukuran atau instrumen mewakili keseluruhan karakteristik isi yang sedang diukur (Sekaran, 2006), dimana : (a) Jika $\rho$-value $<0,05$, maka item pernyataan tersebut valid. (b) Jika $\rho$-value $>$ 0,05 , maka item pernyataan tersebut tidak valid. Sedangkan Uji Reliabilitas menggunakan metoda Internal Consistency, yaitu keseragaman antar-item dalam satu pengukuran untuk mengukur suatu variabel, dengan melihat nilai Cronbach's Coefficient $\alpha$, dimana : (a) Jika Cronbach's Coefficient $\alpha \geq 0,60$, maka item pernyataan tersebut reliable. (b) Jika Cronbach's Coefficient $\alpha \leq 0,60$, maka item pernyataan tersebut tidak reliable (Sekaran, 2006).

Tabel 2. Hasil Uji Validitas dan Reliabilitas Konstruk Penelitian

\begin{tabular}{|c|c|c|c|}
\hline Pernyataan & $\rho$-value & $\begin{array}{l}\text { Koefisien } \\
\text { Korelasi }\end{array}$ & $\begin{array}{l}\text { Coefficient } \\
\text { Cronbach's } 0\end{array}$ \\
\hline Trust & & & 0,783 \\
\hline $\begin{array}{l}\text { 1. Saya yakin bahwa informasi yang saya terima dari } \\
\text { restoran ini akurat. }\end{array}$ & 0,000 & 0,840 & \\
\hline $\begin{array}{l}\text { 2. Saya yakin bahwa restoran ini akan bertindak adil } \\
\text { dan jujur. }\end{array}$ & 0,000 & 0,860 & \\
\hline $\begin{array}{l}\text { 3. Saya selalu bisa mengandalkan informasi dari } \\
\text { restoran ini tentang produk baru yang ditawarkan. }\end{array}$ & 0,000 & 0,854 & \\
\hline $\begin{array}{l}\text { 4. Saya dan restoran ini saling percaya satu dengan } \\
\text { yang lain untuk menjaga hubungan baik. }\end{array}$ & 0,000 & 0,815 & \\
\hline $\begin{array}{l}\text { 5. Cara restoran ini dalam melayani saya dapat } \\
\text { dipercaya. }\end{array}$ & 0,000 & 0,869 & \\
\hline 6. Saya percaya pada restoran ini. & 0,000 & 0,881 & \\
\hline 7. Pelayanan restoran ini sesuai dengan promosi-nya. & 0,000 & 0,867 & \\
\hline $\begin{array}{l}\text { 8. Restoran ini mampu menjaga hubungan baik dengan } \\
\text { saya. }\end{array}$ & 0,000 & 0,827 & \\
\hline $\begin{array}{l}\text { 9. Saya selalu menerima pelayanan yang baik dari } \\
\text { restoran ini. }\end{array}$ & 0,000 & 0,906 & \\
\hline 10. Saya yakin untuk terus mempercayai restoran ini. & 0,000 & 0,924 & \\
\hline $\begin{array}{l}\text { 11. Saya senang dengan pelayanan yang diberikan oleh } \\
\text { restoran ini. }\end{array}$ & 0,000 & 0,899 & \\
\hline $\begin{array}{l}\text { 12. Saya bersyukur mendapatkan pengalaman yang } \\
\text { menyenangkan dari restoran ini. }\end{array}$ & 0,000 & 0,870 & \\
\hline $\begin{array}{l}\text { 13. Saya mengapresiasi hal apapun yang dilakukan } \\
\text { restoran ini untuk mendapatkan kepercayaan saya. }\end{array}$ & 0,000 & 0,892 & \\
\hline 14. Saya menyukai cara restoran ini melayani saya. & 0,000 & 0,921 & \\
\hline
\end{tabular}


Lanjutan Tabel 2.

\begin{tabular}{lcc}
$\begin{array}{l}\text { 15. Restoran ini menghargai saya untuk menjaga } \\
\text { hubungan baik. }\end{array}$ & 0,000 & 0,910 \\
$\begin{array}{lll}\text { 16. Restoran ini menghormati saya sebagai pelanggan. } & 0,000 & 0,888\end{array}$ \\
\hline
\end{tabular}

\begin{tabular}{llll}
\hline Commitment & & & \\
\hline Affective commitment & 0,000 & 0,757 \\
\hline 1. Saya menyukai merek restoran ini. & 0,000 & 0,890 \\
2. Merek restoran ini memberikan banyak arti bagi saya. & $0,0,868$ \\
$\begin{array}{l}\text { 3. Saya memiliki hubungan yang kuat dengan merek } \\
\text { restoran ini. }\end{array}$ & 0,000 & 0,868
\end{tabular}

\begin{tabular}{ll}
\hline Continuance commitnent & 0,789
\end{tabular}

1. Walaupun saya mau, akan tetapi berat untuk berganti $0,000 \quad 0.986$ restoran yang lain.

2. Perasaan saya akan terganggu bila harus berpindah $0,000 \quad 0,884$ ke restoran yang lain.

3. Untuk berpindah ke restoran lain, membutuhkan $0,000 \quad 0,895$ biaya yang sangat mahal.

\begin{tabular}{llll}
\hline Repurchase intention & & & 0,847 \\
1. Saya berniat untuk datang kembali ke restoran ini. & 0,000 & 0,950 & \\
2. Saya ingin kembali ke restoran ini. & 0,000 & 0,905 & \\
3. Saya berharap akan datang kembali ke restoran ini. & 0,000 & 0,948 &
\end{tabular}

Catatan: Semua Variabel Reliabel dan semua Item Valid

Berdasarkan Tabel 2 dapat dijelaskan bahwa: (1) p-value yang diperoleh dari masing-masing konstruk (Trust yang diukur dengan 16 item pernyataan, Affective Commitment, Continuance commitment dan Repurchase intention yang masing-masing diukur dengan 3 item pernyataan) memiliki $p$-value $<0,05$ dan tidak ada indikator dari masing-masing konstruk memiliki $p$-value $>0,05$. Selain itu, nilai koefisien korelasi yang diperoleh dari masing-masing konstruk menunjukkan bahwa setiap indikator memiliki hubungan yang kuat dengan konstruk yang bersangkutan ; sehingga dapat disimpulkan bahwa semua indikator mampu menjelaskan dan mendefinisikan masing-masing konstruk, atau dengan kata lain setiap indikator untuk mengukur masing-masing konstruk yang bersangkutan valid. (2) Nilai Cronbach's Coefficient $\alpha$ untuk masing-masing konstruk, yaitu sebesar telah memenuhi nilai Cronbach's Coefficient $\alpha$ yang dipersyaratkan yaitu $\geq$ 0,60 , sehingga dapat dikatakan bahwajawaban responden terhadap pernyataan-pernyataan yang digunakan dalam penelitian untuk nmengukur masing-masing konstruk Trust, Affective Commitment, Continuance commitment dan Repurchase intention dapat diandalkan/reliabel/konsisten.

Data primer yang digunakan dalam penelitian merupakan data yang dikumpulkan secara langsung oleh peneliti untuk menjawab masalah penelitian. Unit analisis dalam penelitian ini adalah restoran waralaba lokal sebanyak 22 restoran. Sampel sebanyak 210 pengunjung restoran waralaba lokal yang dibagi secara merata sebagai unit observasi diminta untuk mengisi kuesioner. Sampel dipilih dengan menggunakan teknik Purposive Sampling, yaitu dengan kriteria tertentu. Adapun kriteria sampel yang dipilih adalah pengunjung restoran waralaba lokal minimal 2 kali dalam 12 bulan terakhir.

Dari seluruh data yang dikumpulkan, dapat disimpulkan bahwa mayoritas responden jenis kelamin Wanita, siswa maupun mahasiswa, berusia 21 sampai 30 tahun, berpenghasilan Rp1.000.000,- sampai dengan Rp3.000.000,- / bulan. Sedangkan 
minoritas responden adalah berjenis kelamin Pria, Pegawai Negri, berusia diatas 50 tahun, berpenghasilan $<$ Rp500.000,- / bulan.

Structural Equation Model (SEM) merupakan metoda analisis data yang digunakan untuk menganalisis pengaruh variabel independent terhadap variabel dependent yang sifatnya membentuk suatu path (jalur) dalam penelitian ini. Dalam hal ini, pengolahan data dibantu program AMOS versi 6.0.

Sebelum menguji hipotesis yang diajukan, terlebih dahulu dilakukan pengujian kesesuaian model (Goodness of fit model) pada model yang diajukan (Proposed model). Uji kesesuaian model atau goodness of fit yang bertujuan mengetahui apakah model yang digunakan layak dan sesuai untuk digunakan dalam penelitian. Pengujian kesesuaian model dilakukan dengan melihat kriteria pengukuran (Ghozali \& Fuad, 2005), dan hasilnya sebagai berikut:

Tabel 3. Pengukuran Tingkat Kesesuaian Model

\begin{tabular}{|c|c|c|c|c|}
\hline $\begin{array}{l}\text { Jenis } \\
\text { Pengukuran }\end{array}$ & $\begin{array}{l}\text { Goodness of } \\
\text { Fit Index }\end{array}$ & $\begin{array}{l}\text { Hasil } \\
\text { Pengukuran }\end{array}$ & Cut-off & Keputusan \\
\hline \multirow[t]{3}{*}{$\begin{array}{l}\text { Incremental } \\
\text { Fit Measures }\end{array}$} & NFI & 0,935 & $\geq 0,900$ & Goodness offit \\
\hline & CFI & 0,985 & $\geq 0,900$ & Goodness of fit \\
\hline & TLI & 0,996 & $\geq 0,900$ & Goodness offit \\
\hline $\begin{array}{l}\text { Parsimonious } \\
\text { Fit Measures }\end{array}$ & CMIN/DF & 2,347 & $\begin{array}{l}\text { Batas bawah } 1 \\
\text { atau batas atas } \\
5\end{array}$ & Goodness of fit \\
\hline
\end{tabular}

Sumber: Data diolah menggunakan AMOS 18.00

Catatan: $N F I=$ Normed Fit Index; CFI = Comparative Fit Index; TLI = Tucker-

Lewis Index; CMIN/DF = Normed Chi Square;

Semua kriteria pengukuran mempunyai goodness of fit index dengan nilai yang dapat diterima pada Nilai yang diharapkan. Hal ini berarti model yang dibangun dapat diterima. Hair et al., (2010), menyatakan bahwa jika terdapat satu atau dua kriteria goodness-of-fit yang telah memenuhi, model dapat dikatakan baik. Oleh karena itu dapat disimpulkan model yang dibangun secara statistik dapat didukung dan sesuai dengan model fit yang ditetapkan, sehingga pengujian Hipotesis dapat dilanjutkan. Adapun dasar pengambilan keputusan uji hipotesis adalah dengan membandingkan besarnya $p$-value dengan level of significant (alpha) sebesar 0,05. Jika $p$-value $<\alpha 0,05$; Ho Ditolak; dan jika $p$-value $>\alpha 0,05$; Ho Gagal untuk Ditolak.

\section{HASIL DAN PEMBAHASAN}

Statistik Deskriptif. Untuk menggambarkan variabel-variabel yang digunakan dalam penelitian, maka dihitung nilai rata-rata dan standard deviasi-nya. Hasil yang diperoleh dapat diuraikan sebagai berikut: (1) Trust, memiliki nilai rata-rata jawaban responden sebesar 3,977; yang berarti konsumen yakin restoran yang dikunjungi memberikan informasi tentang produk yang ada maupun produk baru secara akurat, bertindak adil dan jujur, menjaga hubungan baik, selalu dapat dipercaya (pelayanannya, pengalaman yang diberikan, usaha untuk membuat konsumen percaya), memberikan sesuai dengan yang dijanjikan, menghargai dan menghormati pelanggannya. (2) Affective commitment, 
memiliki nilai rata-rata jawaban responden 4,145; yang berarti bahwa merek restoran yang dikunjungi konsumen: disukai, memberikan banyak arti, dan memiliki hubungan yang kuat dengan mereka. (3) Continuance commitment, memiliki nilai rata-rata jawaban responden sebesar 4,322; yang berarti bahwa jika konsumen pindah ke restoran lain, mereka akan merasa berat, terganggu perasaannya, serta menyadari bahwa hal itu membutuhkan biaya yang sangat mahal. (4) Repurchase intention, dengan nilai rata-rata 4,395; yang berarti di masa yang akan datang, konsumen berniat, ingin, dan berharap akan mengunjungi kembali restoran yang sama. Selanjutnya, nilai standar deviasiyang diperoleh dari semua variabel cenderung rendah (Trust $=0,295$; Affective commitment $=$ 0,433; Continuance commitment $=0,567$; Repurchase intention $=0,747$ ), maka hal ini berarti bahwa penyebaran data cenderung terpusat dan mengindikasikan bahwa data yang dikumpulkan dari masing-masing variabel baik.

Hasil Pengujian Hipotesis. Keseluruhan hasil full model yang dibangun dalam penelitian ini telah memenuhi syarat goodness test of fit, sehingga dapat dikatakan model yang dibangun baik. Selanjutnya pengujian Hipotesis dapat dilanjutkan. Berikut ini adalah hasil pengujian hipotesis yang diperoleh dari hasil pengolahan:

Tabel 4. Hasil Pengujian Hipotesis

\begin{tabular}{|c|c|c|c|c|}
\hline & Hipotesis & $\begin{array}{l}\text { Standardized } \\
\text { coefficient } \\
(\beta)\end{array}$ & p-value & Keputusan \\
\hline $\mathrm{H}_{1}$ : & $\begin{array}{l}\text { Terdapat pengaruh positif Trust terhadap Affective } \\
\text { commitment. }\end{array}$ & 0,849 & 0,000 & $\begin{array}{l}\mathrm{H}_{1} \\
\text { Didukung }\end{array}$ \\
\hline $\mathrm{H}_{2}$ : & $\begin{array}{l}\text { Terdapat pengaruh positif Trust terhadap } \\
\text { Continuance commitment. }\end{array}$ & 0,893 & 0,000 & $\begin{array}{l}\mathrm{H}_{2} \\
\text { Didukung }\end{array}$ \\
\hline $\mathrm{H}_{3}$ : & $\begin{array}{l}\text { Terdapat pengaruh positif Affective commitment } \\
\text { terhadap Repurchase intention. }\end{array}$ & 0,827 & 0,000 & $\begin{array}{l}\mathrm{H}_{3} \\
\text { Didukung }\end{array}$ \\
\hline $\mathrm{H}_{4}:$ & $\begin{array}{l}\text { Terdapat pengaruh positif Continuance } \\
\text { commitment terhadap Repurchase intention. }\end{array}$ & 0,799 & 0,000 & $\begin{array}{l}\mathrm{H}_{4} \\
\text { Didukung }\end{array}$ \\
\hline $\mathrm{H}_{5}:$ & $\begin{array}{l}\text { Terdapat pengaruh positif Trust terhadap } \\
\text { Repurchase intention. }\end{array}$ & 0,678 & 0,000 & $\begin{array}{l}\mathrm{H}_{5} \\
\text { Didukung }\end{array}$ \\
\hline
\end{tabular}

Sumber: Hasil Pengolahan Data

$\mathbf{H}_{1}$, terdapat pengaruh positif Trust terhadap Affective commitment. Jika konsumen merasa yakin restoran yang dikunjungi memberikan informasi tentang produk yang ada maupun produk baru secara akurat, bertindak adil dan jujur, menjaga hubungan baik, selalu dapat dipercaya (pelayanannya, pengalaman yang diberikan, usaha untuk membuat konsumen percaya), memberikan sesuai dengan yang dijanjikan, menghargai dan menghormati pelanggannya, maka konsumen akan semakin menyukai merek restoran yang dikunjungi-nya, merasa merek restoran tersebut memberikan banyak arti, dan restoran tersebut semakin memiliki hubungan yang kuat dengan-nya. Hasil penelitian ini konsisten dengan penelitian sebelumnya dari Twing-Kwong et al., (2013) yang menunjukkan bahwa Trust memiliki pengaruh positif terhadap Affective commitment. Kepercayaan merupakan persepsi tentang keandalan dan kejujuran (moral) mitra transaksi (Moorman et al., 1992; Morgan \& Hunt, 1994). Oleh karena itu, konsumen ingin melihat 
bahwa penyedia dapat dipercaya, dan untuk percaya, konsumen akan melihat tindakan penyedia jasa apakah sesuai dengan apa yang disepakati (Chauduri \& Holbrook, 2001). Kepercayaan dapat menuntun kepada komitmen, karena kepercayaan menciptakan hubungan pertukaran yang bernilai tinggi (Moorgan \& Hunt, 1994; Chaudhuri \& Holbrook, 2001). Evaluasi keseluruhan atas suatu merek, apa yang dipercayai oleh konsumen mengenai merek-merek tertentu, sejauh apa konsumen percaya bahwa produk atau jasa tersebut memiliki atribut atau keuntungan tertentu, dan penilaian evaluatif terhadap kepercayaan tersebut bagaimana baik atau buruknya suatu produk jika memiliki atribut atau keuntungan tersebut akan membentuk komitmen konsumen terhadap suatu merek perusahaan / produk (Wilkins, 2006).

H2, terdapat pengaruh positif Trust terhadap Continuance commitment. Jika konsumen merasa yakin restoran yang dikunjungi memberikan informasi tentang produk yang ada maupun produk baru secara akurat, bertindak adil dan jujur, menjaga hubungan baik, selalu dapat dipercaya (pelayanannya, pengalaman yang diberikan, usaha untuk membuat konsumen percaya), memberikan sesuai dengan yang dijanjikan, menghargai dan menghormati pelanggannya, maka konsumen akan semakin merasa bahwa pindah ke restoran lain, mereka akan merasa berat, terganggu perasaannya, serta menyadari bahwa hal itu membutuhkan biaya yang sangat mahal. Hasil penelitian ini juga konsisten dengan penelitian sebelumnya dari Twing-Kwong et al., (2013) yang menunjukkan bahwa Trust memiliki pengaruh positif terhadap Continuance commitment. Suatu merek yang sukses selain harus memiliki keunikan, juga harus dapat membuat konsumen percaya terhadap merek tersebut sehingga merek dapat menjadi asset merek / brand equity bagi perusahaan (Crosby et al., 1990). Bagi konsumen, kepercayaan terhadap merek dapat mengurangi tingkat ketidakpastian dan resiko tehadap merek (Chaudhuri \& Holbrook, 2001), seperti informasi tidak pasti yang dihadapi konsumen di pasar, ataupun merek dengan image negatif (Doney \& Cannon, 1997). Kepercayaan konsumen pada merek juga akan semakin memperkuat hubungan antara konsumen terhadap merek yang mereka gunakan sehingga membuat konsumen enggan untuk mencoba produk dengan merek lain (Aaker \& Brasel, 2004), hal ini berarti dapat membangun hubungan jangka panjang (Balleseter \& Aleman, 2000; Morgan \& Hunt, 1994). Kepercayaan konsumen terhadap merek dapat memberikan kontribusi terhadap komitmen pada merek tersebut yang pada akhirnya akan mempengaruhi kesetiaan konsumen jangka panjang (Balleseter \& Aleman, 2000; Hess, 1995).

H3, terdapat pengaruh positif Affective commitment terhadap Repurchase intention. Jika konsumen semakin menyukai merek restoran yang dikunjungi-nya, merasa merek restoran tersebut memberikan banyak arti, dan restoran tersebut semakin memiliki hubungan yang kuat dengan-nya, maka di masa yang akan datang, konsumen berniat, ingin, dan berharap akan mengunjungi kembali restoran yang sama. Hasil penelitian ini juga konsisten dengan penelitian sebelumnya dari Twing-Kwong et al., (2013). Attachment melibatkan hubungan kognitif dan emosional antara individu dan merek (Chaplin \& Roedder, 2005; Escalas \& Bettman, 2003; Escalas, 2004). Hubungan kognitif dan emosional melibatkan berbagai perasaan, termasuk kesedihan dan kecemasan jika berpisah dari merek, kebahagiaan dan kenyamanan dengan merek yang bersangkutan, serta perasaan bangga dengan merek tersebut (Mikulincer \& Shaver 2007; Thomson et al., 2005). Konsumen yang merespon secara emosional pada perusahaan akan komit untuk melakukan pembelian kembali dan akan merekomendasikan perusahaan secara positif kepada pihak lain (Carroll \& Ahuvia, 
2006). Kepercayaan konsumen pada perusahaan adalah penting untuk membentuk attachment / ikatan emosi konsumen pada perusahaan, yang pada akhirnya akan mempengaruhi penilaian konsumen terhadap kinerja masa depan perusahaan (Park \& MacInnis, 2006).

H4, terdapat pengaruh positif Continuance commitment terhadap Repurchase intention. Jika konsumen semakin merasa berat untuk pindah ke restoran lain, terganggu perasaannya, serta menyadari bahwa hal itu membutuhkan biaya yang sangat mahal, maka di masa yang akan datang, konsumen semakin berniat, ingin, dan berharap akan mengunjungi kembali restoran yang sama. Hasil penelitian ini juga konsisten dengan penelitian sebelumnya dari Twing-Twing-Kwong et al., (2013). Evaluasi keseluruhan atas suatu merek akan menghasikan penilaian tentang baik buruk, dan dapat dipercaya atau tidaknya merek akan membentuk sikap konsumen terhadap suatu merek perusahaan / produk (Wilkins, 2006). Sikap terhadap merek dinilai secara positif tergantung pada merek tersebut lebih dipilih di banding merek pesaing (Jin, 2004), lebih disukai dan diingat (Till \& Baack, 2005). Sikap positif konsumen akan menentukan keputusan pembeliannya di masa yang akan datang (Taylor \& Hunter, 2003). Selanjutnya, Lacey \& Morgan (2009) berpendapat bahwa niat membeli kembali merupakan hasil dari perilaku pelanggan yang berkomitmen. Pelanggan yang berkomitmen tidak hanya diharapkan untuk mempertahankan hubungan bisnis, tetapi untuk meningkatkan aktivitas pembelian mereka dari waktu ke waktu (Gronroos, 2004).

H5, Berdasarkan hasil pengujian Hipotesis, dapat disimpulkan bahwa terdapat pengaruh positif Trust terhadap Repurchase intention. Hasil pengujian ini konsisten dengan penelitian sebelumnya yang dilakukan oleh Mosavi \& Ghaedi (2012) yang mengidentifikasi pengaruh meningkatnya Trust terhadap Repurchase intention. Kepercayaan yang tinggi dalam bekerjasama akan menghasilkan transaksi dan kepuasan yang tinggi. Kepercayaan pelanggan dibutuhkan perusahaan untuk membangkitkan loyalitas pelanggan terhadap perusahaan. Pelanggan yang telah memiliki loyalitas kepada perusahaan cenderung melakukan transaksi berulang dan mencari apa yang dibutuhkannya kepada perusahaan tersebut (Thorsten et al., (2002). Hal ini sejalan dengan penelitian yang dilakukan, dimana ditemukan konsumen percaya terhadap restoran waralaba lokal (Mean $=3,977$ ). Kepercayaan tersebut akan membuat konsumen semakin berniat, ingin, dan berharap akan mengunjungi kembali restoran yang sama di masa datang (Mean = 4,395).

Untuk menjelaskan pengaruh tidak langsung Affective commitment dan Continuance commitment, maka dari hasil penelitian dapat dijelaskan sebagai berikut: (1) Pengaruh langsung Trust terhadap Repurchase intention diperoleh nilai Standardized Regression Weights $(\beta)$ sebesar 0,678. Pengaruh langsung Trust terhadap Affective commitment diperoleh nilai $\beta$ sebesar 0,849 . Selanjutnya pengaruh langsung Affective commitment terhadap Repurchase intention diperoleh $\beta=0,827$. Oleh karena itu, pengaruh tidak langsung Trust terhadap Repurchase intention melalui Affective commitment sebesar 0,702 . Oleh karena $0,702>0,678$, maka dapat disimpulkan bahwa pengaruh tidak langsung Trust terhadap Repurchase intention melalui Affective commitment lebih kuat daripada pengaruh langsung Trust terhadap Repurchase intention; atau dengan kata lain Affective commitment merupakan variabel mediasi pengaruh Trust terhadap Repurchase intention. (2) Pengaruh langsung Trust terhadap Continuance commitment diperoleh nilai $\beta$ sebesar 0,893. Selanjutnya pengaruh langsung Continuance commitment terhadap 
Repurchase intention diperoleh $\beta=0,799$. Oleh karena itu, pengaruh tidak langsung Trust terhadap Repurchase intention melalui Continuance commitment sebesar 0,714. Oleh karena 0,714 >0,678, maka dapat disimpulkan bahwa pengaruh tidak langsung Trust terhadap Repurchase intention melalui Continuance commitment lebih kuat daripada pengaruh langsung Trust terhadap Repurchase intention; atau dengan kata lain Continuance commitment merupakan variabel mediasi pengaruh Trust terhadap Repurchase intention.

Selanjutnya dapat diketahui bahwa Continuance commitment merupakan faktor yang lebih kuat dalam mempengaruhi Trust, dan Repurchase intention. dibandingkan Affective commitment.

\section{PENUTUP}

Simpulan. Berdasarkan hasil dari analisis data dalam penelitian ini, dapat disimpulkan: (1) Penelitian yang dilakukan konsisten dengan penelitian yang dilakukan oleh TwingKwong et al., (2013) dan Mosavi \& Ghaedi (2012). (2) Seluruh Hipotesis yang diujididukung; hal ini berarti bahwa: (a) terdapat pengaruh positif Trust terhadap Affective commitment, (b) terdapat pengaruh positif Trust terhadap Continuance commitment, (c) terdapat pengaruh positif Affective commitment terhadap Repurchase intention, (d) terdapat pengaruh positif Continuance commitment terhadap Repurchase intention, dan (e) terdapat pengaruh positif Trust terhadap Repurchase intention. (3) Affective commitment dan Continuance commitment merupakan variabel mediasi pengaruh Trust terhadap Repurchase intention.

Implikasi Manajerial. Untuk menghadapi persaingan dengan restoran waralaba asing, manajer pemasaran sebaiknya lebih mempertimbangkan aspek memelihara hubungan jangka panjang dengan konsumen. Pertimbangan tersebut akan mendatangkan keuntungan bagi perusahaan karena di masa yang akan datang, konsumen berniat, ingin, dan berharap akan mengunjungi kembali restoran yang sama. Hal tersebut dapat tercapai, jika manajer pemasaran lebih peka untuk menciptakan dan memelihara kepercayaan dan komitmen konsumen pada restoran-nya. Beberapa hal yang dapat disarankan untuk hal tersebut adalah : (1) Untuk meningkatkan Trust, dapat disarankan agar manajer dapat : memberikan pelatihan tentang produk, sikap serta perilaku bagi karyawan restoran sebagai ujung tombak perusahaan. Hal ini dimaksudkan agar karyawan dapat memberikan informasi yang akurat bagi konsumen tentang hal apapun yang ingin diketahui konsumen untuk menciptakan pengetahuan konsumen tentang perusahaan atau produk yang ditawarkan. Disamping itu, pelatihan ditujukan agar karyawan dapat secara kontinu dan konsisten memberikan pelayanan yang baik kepada konsumen, menghormati serta menghargai konsumen. (2) Untuk meningkatkan Commitment, maka dapat disarankan agar manajer dapat meningkatkan brand equity-nya, dengan cara meningkatkan citra merek restoran, sehingga merek-nya kuat, unik, dan familiar. Peningkatan citra merek restoran dapat diciptakan melalui aggressive mass marketing campaign. Apabila kepercayaan konsumen akan merek sudah terbentuk, maka akan berdampak pada sikap positif (attitude), ikatan emosional (attachment), serta komitmen (commitment) konsumen pada merek. (3) Untuk menjaga hubungan baik dan jangka panjang, manajer dapat menerapkan (a) loyalty program dengan memberikan reward kepada konsumen sehingga konsumen merasa bahwa pelayanan yang diberikan mempunyai banyak makna bagi 
konsumen, seperti memberikan voucher makan gratis bagi konsumen yang telah berkunjung beberapa kali, serta (b) melakukan kegiatan promosi yang menarik minat konsumen untuk membeli, seperti memberikan diskon harga untuk menu favorit konsumen.

Saran. Dalam setiap penelitian tentu ada keterbatasan. Beberapa keterbatasan dalam penelitian ini, yang dapat disarankan bagi peneliti selanjutnya adalah: (1) Diharapkan penelitian selanjutnya dapat diterapkan pada jenis store retail lain yang juga menggunakan karyawan garis depan dalam kegiatan operasional perusahaan, seperti pada ritel department store, convenience store, specialty store, supermarket, dan hypermarket. (2) Disarankan untuk penelitian selanjutnya bisa dilakukan pada jenis waralaba jasa lainnya, seperti hotel, pendidikan, bengkel, dan lainnya, (3) Penelitian selanjutnya disarankan untuk dilakukan pada non store retail seperti ritel dengan sistem Multi Level Maketing, ritel yang penjualannya dilakukan melalui internet, atau katalog. (4). Untuk penelitian selanjutnya disarankan menambahkan Service quality dan Customer satisfaction sebagai anteseden dari Trust dan Word-of-mouth sebagai konsekuensi dari Commitment.

\section{DAFTAR RUJUKAN}

Aaker, D.A., Brasel, S.A. (2004) "When good brands do bad". Journal of Consumer Research. 31 (1), 1-16.

Albari. (2012) "Peran dimensi komitmen sebagai faktor pengaruh dalam membangun loyalitas". Jurnal Aplikasi Manajemen. 10 (2).

Ballester, Elena, Delgado., and Aleman, Jose, Luis, Munuera. (2000) "Brand trust in the context of consumer loyalty". European Journal of Marketing. 35 (11/12), 12381258.

Bharadwaj, S.G., Vanradarajan, P.R., and Fahy, J. (1993) "Sustainable competitive advantage in service industries: a conceptual model and research propositions". Journal of Marketing. 57, 83-99.

Bloemer, J., de Ruyter, K., and Wetzels, M. (1999) "Linking perceived service quality and service loyalty: a multi-dimensional perspective". European Journal of Marketing. $33(11 / 12), 1082-1106$.

Callaghan, M. B., McPhail, J., and Yau, O. H. A. (1995) "Dimensions of a Relationship Marketing Orientation: An Empirical Exposition". Proceedings of the Seventh BiAnnual World Marketing Congress. II, 10.56-10.66.

Carroll, B., and Ahuvia, A. (2006) "Some antecedents and outcomes of brand love". Marketing Letters. 17 (2), 79-89.

Chaudhuri, A., and Holbrook, M.B. (2001) "The chain of effects from brand trust and brand affect to brand performance: the role of brand loyalty". Journal of Marketing. 65 (2), 81-93.

Chaplin, Nguyen., and Roedder, D. J. (2005) "The Development of Self-Brand Connections in Children and Adolescents". Journal of Consumer Research. 32 (1), 119-129.

Chow, S., and Holden, R. (1997) "Towards an Understanding of Loyalty: The Moderating Role of Trust”. Journal of Marketing Issues. 9 (3), 275-298. 
Crosby, L.A., Evans, K.R., and Cowles, D. (1990) "Relationship Quality in Services Selling: An Interpersonal Influence Perspective". Journal of Marketing. 54 (3), 6881.

Day, C. (2000) "Stories of Change and Professional development: The costs of commitment", In C. Day, A. Fernandez, T. Hauge, \& J. Moller (Eds.), The life and work of teachers: International perspectives in changing times (pp. 109-129). London: Falmer Press.

Doney, P.M., and Cannon, J.P. (1997) "An examination of the nature of the trust in buyerseller relationships". Journal of Marketing. 61, 35-51.

Dunia Riset. (2013) Brand Switching Analysis dalam Industri Ritel Modern. http://www.marketing.co.id/brand-switching-analysis-dalam-industri-ritel-modern. Diunduh 15 November 2015.

Eastlick, M. A., and Lotz, S. (2011) "Cognitive and institutional predictors of initial trust toward and online retailer". International Journal of Retailing and Distribution Management. 39 (4), 235-55.

Escalas, Jennifer E., and Bettman, J. R. (2003) "You Are What They Eat: The Influence of Reference Groups on Consumers' Connections to Brands". Journal of Consumer Psychology. 13 (3), 339-348.

. (2004) "Narrative Processing: Building Consumer Connections to Brands". Journal of Consumer Psychology. 14 (1-2), 168-79.

Fajri, Laila, Nurul. (2012) "Analisis Kesesuaian Lokasi Minimarket di Kecamatan Lembang Kabupaten Bandung Barat". Universitas Pendidikan Indonesia.

Jones, T. D. (2003) "Personal, professional, and service company commitments in service relationships". Doctoral Dissertation. Queen's University.

Garbarino, E., and Johnson, M. S. (1999) "The different roles of satisfaction, trust and commitment in customer relationships". Journal Marketing. 63, 70-87.

Ghozali, Imam., and Fuad. (2005) Structural Equation Modelling: Pengantar. Badan Penerbit Universitas.

Gounaris, S.P., Stathakopoulos, V., and Athanassopoulus, A.D. (2003) "Antecedents to perceived service quality: an exploratory study in the banking industry". The International Journal of Bank Marketing. 21 (4/5), 168-190.

Griffin, J. (1995) Customer Loyalty. How to Earn It, How to Keep It. New York, USA: Lexington Books.

Gronroos, C. (2004) "The relationship marketing process: communication, dialogue, and value". Journal Business Industrial Marketing. 19 (2), 99-113.

Gundlach, G. T., Ravi, S. A., and John, T. M. (1995) "The structure of commitment in exchange". Journal of Marketing. 59, 72-92.

Hair, J. F., Black, W. C., Babin, B. J., and Anderson, R. E. (2010) Multivariate Data Analysis. 7th edn. Prentice Hall.

Hellier, P.K., Geursen, G.M., and Rickard, J.A. (2003) "Customer repurchase intention, a general structural equation model". European Journal of Marketing. 37 (11/12): 1762-1800.

Hess, J. (1995) "Construction and Assessment of a scale to measure consumer trust". American Marketing Association, Chicago, IL, Summer. 6, 20-26.

Hennig-Thurau, T., and Klee, A. (1997) "The Impact of Customer Satisfaction and Relationship Quality and Customer Retention: a Critical Reassessment and Model Development". Psychology and Marketing. 14 (8), 737-764. 
Kenning, P. (2008) "The influence of general trust and specific trust on buying behavior", International Journal of Retail and Distribution Management. 36 (6), 461-476.

Kotler, P., Keller, K. L. (2011) Marketing Management. 14th ed. Pearson Prentice Hall.

Koufaris, M., and LaBarbera, P. A. (2002) "Consumer Behavior in Web-Based Commerce: An Empirical Study." International Journal of Electronic Commerce. $62,131-154$

Lacey, R., and Morgan, R. M. (2009) "Customer advocacy and the impact of B2B loyalty programs. Department of Management and Marketing, University of Alabama, Tuscaloo". Journal Business Industrial Marketing. 24 (1), 3-13.

Lau, G., and Lee, S. (1999) "Consumers' Trust in A Brand and Link to Brand Loyalty". Journal of Market Focused Management. 4, 341-370.

Liang, C., and Wang, W. (2005) "Integrative research into the financial services industry in Taiwan: Relationship bonding tactics, relationship quality and behavioural loyalty". Journal of Financial Services Marketing. 10 (1), 65-83.

Louis, Didier., and Lombart, Cindy. (2010) "Impact of brand personality on three major relational consequences (trust, attachment, and commitment to the brand)". Journal of Product \& Brand Management. 19 (2), 114-130.

McAllister, D. J. (1995) "Affect and cognitive-based trust as foundations for interpersonal cooperation in organizations". Academy of Management Journal. 38 (1), 24-59.

Meryani, Andina. (2011) Kian Menjamur, Bisnis Ritel Makin Menggiurkan.

Meyer, John, P., and Smith. A. (2000) "HRM Practices and Organizational Commitment: Test of Mediation Model". Canadian Journal of Administrative Science. 17 (4), 319331.

Meyer, John P., and Allen, Natalie J. (1997) "Commitment in the Workplace: Theory, Research and Application”. Thousands Oaks, CA: Sage.

Mikulincer, Mario., and Shaver, P. R. (2003) "The attachment behavioral System in adulthood: Activation, Psychodynamics, and Interpersonal processess". Advances in Experimental Social Psychology. Mark P. Zanna.,ed. New York: Academic Press.

Mittal, B., and Lassar, W.M. (1998) "Why do customers switch? The dynamics of satisfaction versus loyalty". The Journal of Services Marketing. 12 (3), 177-194.

Moorman, C., Zaltman, G., and Deshpande, P. (1992) "Relationships between providers and users of marketing research: the dynamics of trust within and between organizations", Journal of Marketing Research. 29 (3), 314-329.

Morgan, R.M., and Hunt, S. (1994) "The commitment-trust theory of relationship marketing". Journal of Marketing. 58 (July), 20-38.

Mosavi, S. A., and Ghaedi, M. (2012) "A survey on the relationship between trust, customer loyalty, commitment and repurchase intention". African Journal of Business Management. 6 (36), 10089-10098.

Park, C. Whan., and MacInnis, Deborah, J. (2006) "What's In and What's Out: Questions on the Boundaries of the Attitude Construct". Journal of Consumer Research. 33 (June), 16-8.

Reichheld, F.F., and Sasser, W.E. (1990) "Zero defections: quality comes to services". Harvard Business Review. 68 (5), 105-111.

(1996). The Loyalty Effect. Harvard Business School Press, Boston, MA.

Rowley, J., and J. Dawes. (1999) "Customer Loyalty-a Relevant Concept for Libraries?". Library Management. 20 (6), 345-351.

Sheth, J. N., and Mittal, B. (2004) Customer Behaviour: A Managerial Perspective. 
Singh, J. (1991) "Understanding the structure of consumers satisfaction evaluations of service delivery". Journal of The Academy of Marketing Science. 19, 223-244.

Sekaran, Uma. (2006) "Research Methods For Business - A Skill Building Approach". Fourth Edition. John Wiley \& Sons, Inc.

Sudarmiatin. (2011) Praktik Bisnis Waralaba (Franchise) Di Indonesia, Peluang Usaha dan Investasi. Pidato Pengukuhan Guru Besar dalam Bidang Ilmu Manajemen pada Fakultas Ekonomi Universitas Negeri Malang.

Sujana, Asep. (2005) Manajemen Ritel Modern. Yogyakarta: Graha Ilmu.

Taylor, S. A., and Hunter, G. (2003) "An exploratory investigation into the antecedents of satisfaction, brand attitude, and loyalty within the (B2B) eCRM Industry". Journal of Consumer Satisfaction, Dissatisfaction and Complaining Behavior. 16 (1), 19-35.

Terrill, C., Middlebrooks, A., and American Marketing Association. (2000) "Market Leadership Strategies For Service Companies: Creating Growth, Profits, and Customer Loyalty”. NTC/Contemporary Publishing, Lincolnwood, IL.

Thomson, Matthew., MacInnis, Deborah, J., and Park, C, Whan. (2005) "The ties that bind: measuring the strength of consumer's attachments to brands". Journal of Consumers Psychology. 15 (1), 77-91.

Till, D. Brian., and Baack, Daniel. (2005) "Recall and Persuasion, Does Creative AdvertisingMatter ". Journal of Advertising. 34 (3).

Twing-Kwong, S., Albaum, L. G., and Fullgrabe, L. (2013) "Trust in customer salesperson relationship in China's retail sector". International Journal of Retail \& Distribution Management. 41(3), 226-248.

Wang, Jau-Shyong. (2009) "Trust and relationship commitment between direct selling distributors and customers". African Journal of Business Management. 3 (12), 862870.

Wardhana, Edwin (2012) Perkembangan Franchising di Indonesia.

Wilkins, H.C. (2006) "A Structural Model of Satisfaction and Brand Attitude in Hotels". Journal of Consumer Research.

Zeithaml, V., Bitner, M.J. (1996) Service Marketing. New York. Mc Graw Hill Companies Inc.

Zur, A., Leckie, C., and Webster, C. M. (2012) "Cognitive and affective trust between Australian exporters and their overseas buyers". Australasian Marketing Journal. 20 (1), 73-79. 